\title{
A INFLUÊNCIA DA CONTABILIDADE DE CUSTOS E DO PROFISSIONAL CONTABILISTA NA FORMAÇÃO DO PREÇO DE VENDA DAS MICRO E PEQUENAS EMPRESAS DE PORTO VELHO
}

\author{
THE INFLUENCE OF COSTS ACCOUNTING AND \\ PROFESSIONAL ACCOUNTANT ON THE TRAINING OF \\ SALES PRICE OF MICRO AND SMALL ENTERPRISES IN \\ PORTO VELHO CITY
}

Recebido: 02/02/2016 - Aprovado: 20/04/2016 - Publicado: 30/06/2016 Processo de Avaliação: Double Blind Review

\author{
César Licório ${ }^{1}$ \\ Mestre em Contabilidade \\ Fatec-Rondônia \\ clicorio@ hotmail.com
}

\author{
Eduardo Galindo de Souza \\ Graduado em Ciências Contábeis \\ Fatec-Rondônia \\ egalindosouza@bol.com.br
}

\author{
Joanílson de Lima Dias \\ Graduado em Ciências Contábeis \\ Fatec-Rondônia \\ nylson_cb546@hotmail.com
}

\section{Marcos dos Santos Melo}

Especialista em Gestão empresaria e em Metodologia do Ensino

Fatec-Rondônia

melo_mh@hotmail.com

RESUMO: O objetivo deste trabalho é identificar a contribuição de contabilidade de custos e contador profissional, como uma vantagem competitiva na formação do preço de venda das micro e pequenas empresas na cidade de Porto Velho. A metodologia utilizada para a

\footnotetext{
${ }^{1}$ Autor para correspondência: Faculdade de Ciências Administrativas e Tecnologia - Avenida Governador Jorge Teixeira, 3500 - Nova Porto Velho, Porto Velho - RO, Brasil, 78906-100.
} 
elaboração do presente trabalho foi o levantamento descritivo e qualitativo, bem como um estudo de campo, utilizando questionário. A partir do seguinte problema: em uma economia globalizada, com tal política de preços agressiva, qual a importância da contabilidade de custos e os conselhos de um contador profissional na formação do preço de venda? Esta pesquisa se justifica no mercado cada vez mais competitivo, como o Porto Velho, onde qualquer detalhe pode trazer uma grande vantagem na linha de fundo. Os principais resultados identificados mostram que a grande maioria dos micro e pequenos empresários de Porto Velho não usam contabilidade de custos, nem a ajuda de um contador, um profissional qualificado com as técnicas necessárias para apoiar a formação de seus preços para que eles não incorram em erros que lhe tragam prejuízos, também, não usam a vantagem da informação que os recursos de contabilidade de custos para tomada de decisão. Numa economia globalizada, especificamente em um mercado em crescimento como o Porto Velho qualquer detalhe pode fazer a diferença entre o sucesso e o fracasso de um negócio micro e pequenas, contabilidade de custos se torna uma ferramenta cada vez mais necessária, e, é inegável à contribuição que o contador, como um profissional especializado, pode trazer ao gerente, dando-lhe condições para formar seus preços, decidindo estratégias de marketing e controlar os custos.

Palavras-chave: Contabilidade de Custos; Contador; preço das vendas.

ABSTRACT: The aim of this paper is to identify the contribution of cost accounting and professional accountant, as a competitive advantage in the formation of the selling price of micro and small enterprises in Porto Velho city. The methodology used for the preparation of this work was a survey, of course, literature, descriptive and qualitative, as well as a field study using questionnaire. Starting from the following problem: in a globalized economy, with such aggressive pricing, which the importance of cost accounting and the advice of a professional accountant in the formation of the selling price? This research is justified in the increasingly competitive market, such as the Old Port, where any detail can bring a great advantage in the bottom line. The main results identified show that the vast majority of micro and small entrepreneurs of Porto Velho do not use cost accounting, nor the aid of a counter, a qualified professional with the necessary techniques to support the formation of their prices so they do not incur errors that bring you losses also do not use the advantage of the information that the cost accounting features for decision making. In a globalized economy, 
specifically in a growing market as the Porto Velho any detail can make the difference between success and failure of a micro and small business, cost accounting becomes an increasingly necessary tool, and it is undeniable the contribution that the counter as specialized professional can bring to the manager has grounds to form their prices, deciding marketing strategies, and control costs.

Keywords: Cost accounting. Accountant. Sales price.

\section{INTRODUÇÃO}

No Brasil a maioria das empresas faz parte do grupo das micro e pequenas empresas (MPE’s), e, em Porto Velho, essa realidade não é diferente. Segundo dados da junta comercial de Rondônia, Porto Velho possui 43.402 microempresas e 2.394 empresas de pequeno porte, a quantidade de empresas com estrutura diferente, ainda segundo a junta comercial, é irrisória. Uma característica das MPE’s é a simplicidade em sua estrutura administrativa, e um reflexo disto, pode ser observado no fato de não conhecerem as técnicas de formação de preços e os custos de seus produtos. Em decorrência disto, os micro e pequenos empresários, muitas vezes, acabam por fixar seus preços de forma equivocada, sem nenhum critério e acabam incorrendo em prejuízos, inviabilizando o negócio.

O mercado atual é bastante competitivo, e, para as MPE’s não é diferente e é uma boa estrutura de custos que pode ser usada como vantagem competitiva, pois os preços praticados pelo mercado são bastante agressivos.

Figueiredo e Caggiano (2004) afirmam que a estrutura de custos elaborada de forma correta tem a capacidade de determinar, a curto prazo, se o preço adotado irá gerar lucro ou prejuízo por cada unidade vendida, porém alertam que o lucro total dependerá de diversos fatores alheios à empresa como demanda, elasticidade, aspectos mercadológicos, entre outros.

O cálculo dos custos de forma inadequada pode conduzir às informações que não condizem com a realidade, cujos reflexos afetarão diretamente nas decisões baseadas nos mesmos, inclusive às relativas ao problema do estabelecimento do preço de venda. A contabilidade de custos e a informação que ela oferece, porém, só poderão ser aproveitadas em sua totalidade com o auxílio de um profissional que a interprete e extraia dela todo o seu potencial. Neste momento, se torna imprescindível a assessoria a um profissional contabilista.

O processo de formação do preço de venda, segundo Santos (2010), é o processo em que determinada empresa, com base em seus custos, suas estimativas de venda além de outros 
fatores que estão ligados à sua produção ou operação, encontra o preço ideal para a venda de seus produtos ou serviços. Ainda segundo Santos (2010), existem basicamente dois pontos de vista a serem observados na formação do preço de venda: o primeiro considera que os preços de qualquer organização são definidos apenas pelo mercado e o segundo prega que é necessário o cálculo econômico para boas decisões de preços. Se essas visões forem respeitadas de forma separada, se tornam muito limitadas. Sendo assim, elas devem coexistir dentro da organização para se chegar ao preço ideal.

A formação do preço de venda é uma peça fundamental para a continuidade da empresa, seja ela de grande porte, ou uma MPE. Segundo Hoji (2004), se o preço for muito alto poderá atrapalhar a venda, todavia se for muito baixo corre o risco de não cobrir os custos e despesas. A fixação do preço de venda é uma das mais difíceis decisões de se tomar na gestão de uma empresa, e nas MPE's se torna mais difícil ainda devido à falta de subsídios necessários e pela falta de assessoria de um profissional capacitado qual seja este o profissional contabilista.

Diante desse cenário, questiona-se: em uma economia globalizada, com preços tão agressivos, qual a importância da contabilidade de custos e da assessoria de um profissional contabilista na formação do preço de venda?

Tendo em vista o exposto, ficou definido como objetivo geral desta pesquisa: Identificar a contribuição da contabilidade de custos e do contador para as micro e pequenas empresas na busca de uma forma adequada de se calcular o preço de venda, delimitando a pesquisa ao município de Porto Velho, tendo como universo de pesquisa as micro e pequenas empresas.

A presente pesquisa se justifica no mercado cada vez mais competitivo, como o de Porto velho, onde qualquer detalhe pode trazer uma grande vantagem no resultado final da empresa. Apesar de o mercado ditar as regras, é fundamental o uso da contabilidade de custos e o auxílio do contador para a decisão de como formar o preço de venda, sem as informações que a contabilidade de custos fornece, o gestor fica sem elementos necessários para tomar decisões no que se refere à formação do preço de venda, o que, na maioria das vezes, acaba por induzi-lo a tomar decisões equivocadas.

\section{CONTABILIDADE DE CUSTOS}

A contabilidade de custos surgiu da necessidade de resolver problemas de mensuração monetária dos estoques e do resultado, não sendo levado em consideração como 
instrumento de administração, por esse motivo a contabilidade de custos deixou de ter uma evolução mais acentuada por um longo período de tempo (MARTINS, 2003).

Segundo Crepaldi (2010) as últimas décadas têm sido marcadas por uma evolução e modernização da contabilidade de custos, tornando-se um importante instrumento de gestão, subsidiando as tomadas de decisões.

Os estudiosos têm cada vez mais pesquisado a respeito da contabilidade de custos, observando o sistema, as técnicas e suas formas de mensuração e controle. O conceito moderno de contabilidade de custos, segundo Crepaldi (2010, p. 2), seria o seguinte: "Contabilidade de custos é uma técnica utilizada para identificar, mensurar e informar os custos dos produtos e/ ou serviços. Ela tem a função de gerar informações precisas e rápidas para a administração, para a tomada de decisões."

\subsection{CLASSIFICAÇÃO DOS CUSTOS}

Para que a administração possa coletar e utilizar a informação que a contabilidade de custos oferece é necessário uma classificação apropriada.

Segundo Crepaldi (2010) os custos podem ser classificados quanto à apropriação aos produtos em custos diretos e custos indiretos e quanto ao nível de atividade em custos fixos, custos variáveis e custos semivariáveis ou semifixos.

Quanto à sua apropriação aos produtos os custos podem ser:

- Custos Diretos: são aqueles que podem ser diretamente apropriados aos produtos, sendo necessária apenas uma medida de consumo (quilos, horas de mão de obra, embalagens utilizadas) (MARTINS, 2003).

- Custos Indiretos: consiste nos custos que para serem apropriados aos produtos, precisam de algum critério para que haja um rateio. Exemplos: aluguel, depreciação, energia elétrica etc. (CREPALDI, 2010).

- Quanto ao nível de atividades os custos podem ser:

- Custos Fixos: são os custos que não variam proporcionalmente ao volume produzido, ou seja, independe da produção, podendo existir até sem haver produção. Exemplos: aluguel, seguro etc. (CREPALDI, 2010).

- Custos Variáveis: são aqueles que estão diretamente ligados à produção, quanto maior a quantidade produzida maior será o seu consumo, ou seja, 
variam de acordo com o volume de produção. Exemplos: materiais diretos, embalagem etc. (MARTINS 2003).

- Custos Semivariáveis ou Semifixos: segundo Crepaldi (2010, p. 9) "É o custo que varia em função do volume de produção ou venda, mas não exatamente nas mesmas proporções”. Exemplo: energia elétrica R\$100,00 para fabricar até 2000 unidades e $\mathrm{R} \$ 200,00$ para fabricar até 2500 unidades.

\section{MÉTODOS DE CUSTEIO}

Os métodos de custeio nada mais são do que os métodos que são utilizados para a apropriação dos custos incorridos no processo produtivo de forma organizada.

Atualmente existem diversos métodos de custeio atendendo as mais diversas necessidades, porém os que se destacam são o custeio por absorção o custeio variável/direto e o custeio por atividades $\mathrm{ABC}$.

\subsection{CUSTEIO POR ABSORÇÃo}

Para Horngren, Foster e Datar (2000, p.211), “o custeio por absorção é o método de custeio do estoque no qual todos os custos de fabricação, variáveis e fixos são considerados custos inventariáveis, isto é, o estoque absorve todos os custos de fabricação".

Conforme Dubois, Kulpa e Souza (2006, p.124):

Neste método, todos os gastos que participam da elaboração dos produtos fabricados deverão ser absorvidos por eles. Este é o único método de custeio aceito pela Contabilidade Financeira que atende aos princípios contábeis. O custeio de absorção indica que cada unidade produzida "absorveu" todos os gastos necessários para obtê-la, sejam diretos, isto é, próprios do produto, ou indiretos, que são aqueles que auxiliam a produção. Com este método, podem-se apurar os saldos dos estoques, o Custo da Produção Vendida (CPV), além de demonstrar a situação patrimonial no Balanço.

O custeio por absorção é o método que atende aos princípios fundamentais de contabilidade, e, no Brasil, é o único aceito pela legislação comercial e fiscal (CREPALDI, 2010).

\subsection{CUSTEIO VARIÁVEL OU DIRETO}

Para Martins (2003, p. 198), "no custeio variável, só são alocados aos produtos os custos variáveis, ficando os fixos separados e considerados como despesas do período, indo diretamente para o resultado; para os estoques só vão, como consequência, custos variáveis" 
O custeio variável é de grande importância para a tomada de decisões, pois oferece várias ferramentas para tal, dentre elas podemos destacar, a margem de contribuição, o ponto de equilíbrio e a margem de segurança.

\subsubsection{MARGEM DE CONTRIBUIÇÃO}

Segundo Martins (2003), margem de contribuição, nada mais é do que a diferença do preço de venda e o custo variável de cada produto, é o valor que cada unidade produzida traz de retorno a empresa da sobra entre sua receita e o custo que de fato provocou.

Para Crepaldi (2010, p. 236) "A margem de contribuição representa o valor que cobrirá os custos e despesas fixos da empresa e proporcionará o lucro."

Sua formula é assim representada:

$$
M C=R V-(C v u+D V u)
$$

Onde: MC: margem de contribuição

$\mathrm{RV}$ : vendas totais

$\mathrm{CV}$ : custo variável total

\subsubsection{PONTO DE EQUILÍBRIO}

Segundo Crepaldi (2010, p. 239), "é o ponto de equilíbrio onde os custos totais e as receitas totais se igualam. A partir desse ponto, entra na área da lucratividade."

Ou seja, neste ponto a empresa não tem lucro nem prejuízo. Produz o suficiente para sobreviver.

O ponto de equilíbrio subdivide-se em: ponto de equilíbrio contábil que é o ponto de igualdade entre receita total e custo total (CREPALDI, 2010), ponto de equilíbrio econômico que mostra a rentabilidade que a atividade escolhida traz, em confronto com outras opções de investimento (CREPALDI, 2010), e o ponto de equilíbrio financeiro, que é o volume de vendas necessário para que se possam cumprir os compromissos financeiros (CREPALDI, 2010).

\subsubsection{MARGEM DE SEGURANÇA}

Para Crepaldi (2010, p. 249), margem de segurança "é um indicador de risco que aponta a quantidade a que as vendas podem cair antes de se ter prejuízo. É a parcela de produção e vendas que a empresa tem que estar acima do ponto de equilíbrio". 
A margem de segurança pode ser expressa em valor, unidade ou percentual fórmula. Para se calcular a margem de segurança (CREPALDI, 2010) a fórmula para seu cálculo é a seguinte:

$$
M S \%=\frac{\% \text { da Margem de lucro }}{\% \text { da Margem de Contribuição }}
$$

\subsection{CUSTEIO BASEADO EM ATIVIDADES ABC}

Segundo Crepaldi (2010, p.321):

Pode-se definir um custeio por atividade como sendo um método que identifica um conjunto de custos para cada transação ou evento na organização e este age como um direcionador de custos, sendo assim, os custos indiretos podem ser alocados aos produtos de acordo com o número de eventos ou transações que os produtos geram ou consomem.

Padoveze (1994, p.237) considera que:

O custeio ABC procura aprimorar o custeamento dos produtos, através de mensurações corretas dos custos fixos indiretos, em cima das atividades geradoras desses custos, para acumulação diferenciada ao custo dos diversos produtos da empresa.

\section{FORMAÇÃO DO PREÇO DE VENDA}

Preço, de acordo com Dutra (2003, p.32), "é o valor adotado para transferência de um bem, não necessariamente estarão contemplados os custos ou a margem de lucro do mesmo". A formação do preço de venda nada mais é do que o processo necessário para se determinar o correto valor a ser cobrado por um bem ou serviço, para tanto são utilizadas inúmeras técnicas como veremos a seguir. Toda empresa é única e para se chegar ao correto valor do preço é necessário um estudo individual visando encontrar as técnicas mais corretas a serem utilizadas.

\subsection{ADMINISTRAÇÃO ESTRATÉGICA DE PREÇOS}

Segundo Santos (2010), para formular decisões de preço de venda é necessário observar múltiplos fatores, sendo os mais utilizados os fatores de natureza mercadológica e financeira. Sob a ótica estratégica, os preços podem ser observados praticamente de duas formas, a saber: preço de curto prazo e preço de longo prazo.

Segundo Santos (2010, p. 181), "um preço de curto prazo é aquele capaz de permitir o atendimento de um objetivo imediato - financeiro ou não -, mas sem perder de vista os objetivos da empresa em longo prazo". Um exemplo disso são as empresas que começam a 
operar com um preço reduzido para serem elevados pouco a pouco até alcançarem o patamar normal (SANTOS, 2010).

De acordo com Santos (2010, p. 181) "O preço de longo prazo pode ser definido como o preço médio praticado para produtos ou serviços ao longo de seu ciclo de vida ou da vida útil do investimento utilizado para viabilizar sua oferta".

\subsection{POLÍTICA DE PREÇOS}

Entende-se por política de preços o conjunto de ações e diretrizes que vão regular as decisões sobre preço no curto e longo prazo, e as condições em que esses preços são praticados. (SANTOS, 2010).

a) Preço de penetração

Trata-se da política em que determinada empresa utiliza um preço inicial mais baixo para facilitar sua entrada no mercado. Ao praticar essa política, deve-se levar em consideração dois fatores: a rentabilidade em longo prazo e a resposta da concorrência. (SANTOS, 2010)

b) Preço-nata

A prática desta política se dá quando determinada empresa possui um produto que possua características que lhe permita ser vendido por um preço mais alto do que o normal em sua fase de introdução no mercado. Esta prática deve levar em consideração em sua avaliação, antes do lançamento, a redução dos lucros devido à concorrência. (SANTOS, 2010).

c) Preço promocional

Em determinadas circunstâncias, o preço de um produto pode ser reduzido em curtos períodos de tempo. Quando isto ocorre, estamos diante de um preço promocional. Sua adoção e uma medida contingencial adotada geralmente para minimizar perdas, por exemplo, o encalhe de estoques. (SANTOS, 2010)

d) Preços em situação de capacidade ociosa

A capacidade ociosa das empresas pode ser normal ou eventual, normal quando as empresas têm variação da demanda em função das estações do ano, dia da semana ou até mesmo de horários, e eventual quando essa redução da demanda e passageira e provocada por fatores externos. Para a capacidade ociosa normal, é recomendado adotar uma política 
permanente de preços reduzidos, e, para a eventual, o desconto será calculado quando a situação ocorrer. (SANTOS, 2010).

e) Preços para venda financiada

A política de preços para venda financiada defende que deve ser calculado de forma diferente, levando em consideração os riscos corridos como a inadimplência e as taxas de juros. O financiamento das vendas é feito com taxas prefixadas que representam o custo do dinheiro no momento da venda. Além disso, é comum as empresas incluírem em seu preço de venda uma parcela de custo para fazer frente a riscos de perdas por inadimplência. (SANTOS, 2010)

\subsection{MÉTODOS DE FORMAÇÃO DE PREÇO}

\subsubsection{MÉTODO BASEADO NO CUSTO DE COMPRA DA MERCADORIA}

O método mais tradicional entre os gestores de preços é o baseado no custo. Conforme Santos (2005, p. 113):

É o mais comum na prática dos negócios. Se a base for o custo total, a margem adicionada deve ser suficiente para cobrir os lucros desejados pela empresa. Se a base for os custos marginais, a margem adicionada deve cobrir, além dos lucros, os custos fixos. O processo de adicionar margem fixa a um custo-base é geralmente conhecido pela expressão Mark-up.

O Mark up é um método rápido de se apurar o preço de venda, tomando como base o custo de absorção de cada produto. Segundo Padoveze (2010, p. 283), "a partir do custo por absorção de cada produto, aplica-se um multiplicador, de tal forma que os demais elementos formadores do preço de venda sejam adicionados ao custo, a partir desse multiplicador.”

Formulas de cálculos do Mark - up:

$$
\text { Mark }- \text { up multiplicador }=\frac{1}{1-\text { soma das taxas percentuais }}
$$

Mark - up divisor $=1-$ Soma das taxas percentuais

\subsubsection{MÉTODO BASEADO NAS DECISÕES DAS EMPRESAS CONCORRENTES}

De acordo com Santos (2005, p.114), “qualquer método de determinação de preços deve ser comparado com os preços das empresas concorrentes, que porventura existam no 
mercado". Segundo Santos esse método subdivide-se em: método do preço corrente; método de limitação de preços; método de preços agressivos e método de preços promocionais.

\subsubsection{MÉTODO BASEADO NAS CARACTERÍSTICAS DO MERCADO}

Para adotar esse método é necessário um conhecimento amplo do mercado, consiste em estabelecer o preço do produto tomando como base o valor praticado no mercado. Tal conhecimento permite escolher a estratégia para se adotar se o produto pode ser vendido a um preço mais alto, atraindo as classes economicamente mais elevadas, ou a um preço popular, atendo as camadas mais pobres (SANTOS 2010).

\section{METODOLOGIA}

A metodologia empregada no desenvolvimento do presente trabalho quanto à sua natureza caracteriza-se como uma pesquisa aplicada. Segundo Siena (2007, p. 58) entende-se: "por pesquisa aplicada a geração de conhecimentos visando aplicação prática, direcionados para a solução de problemas específicos".

Quanto à forma de abordagem do problema a presente pesquisa pode ser classificada como uma pesquisa qualitativa. Na pesquisa qualitativa o pesquisador é peça essencial, onde sua fonte fundamental de dados é o próprio ambiente natural (SIENA 2007). Algumas características importantes da pesquisa qualitativa segundo Siena $(2007$, p. 60) "o foco não é a quantificação, mas a interpretação dos fenômenos e a atribuição de significados, pois o pesquisador considera que há uma relação dinâmica entre o mundo real e o sujeito que não pode ser quantificável”. Ainda segundo Siena (2007), na pesquisa qualitativa não se usa métodos e técnicas estatísticas, porém é possível usar a estatística descritiva na organização das informações.

No que se refere aos fins da pesquisa, este artigo pode ser emoldurado como uma pesquisa descritiva. O estudo descritivo conforme Gil (1999, p. 44) "tem como principal objetivo descrever características de determinada população ou fenômeno ou o estabelecimento de relações entre variáveis', neste tipo de pesquisa os fenômenos são estudados, todavia não podem ser manipulados, desta forma resta ao pesquisador observar, registrar, analisar, classificar e interpretar os dados (DINIZ 2008). Segundo Siena (2007, p. 64) "Como forma de levantamento, exige o emprego de técnicas padronizadas de coleta de dados, tais como questionário e observação sistemática”. 
Quanto aos procedimentos técnicos da pesquisa, esta, como não poderia ser diferente conforme assevera Siena (2007, p. 65) “[...] este tipo de pesquisa seja parte quase obrigatório em alguns dos estudos [...] ", adotou para a construção de sua fundamentação teórica a pesquisa bibliográfica. Pesquisa bibliográfica na visão de Siena (2007, p. 65) é aquela "Elaborada ou desenvolvida a partir de material já publicado, em geral livros, artigos de periódicos e materiais disponibilizados na Internet”.

Além da pesquisa bibliográfica, foi realizado um estudo de campo visando evidenciar na prática o que foi abordado no referencial teórico da presente pesquisa. O estudo de campo é semelhante ao levantamento, porém as principais características que o diferem são: possui mais profundidade, procura aprofundar o problema em questão além de investigar somente um grupo no que se refere à estrutura social (SIENA 2007).

Existem variados tipos de instrumentos que podem ser utilizados no estudo de campo dos quais destacam-se: questionários, entrevistas, formulários e observação (SIENA 2007). No estudo de campo realizado no presente trabalho optou-se por usar o questionário que segundo Gil (1999, p.128), "é uma técnica de investigação composta por um número mais ou menos elevado de questões apresentadas por escrito às pessoas, tendo por objetivo o conhecimento de opiniões, crenças, sentimentos, interesses, expectativas, situações vivenciadas dentre outras." Os respondentes do referido questionário foram os micros e pequenos empresários.

\section{APRESENTAÇÃO E ANÁLISE DOS DADOS}

Neste capítulo serão apresentados os dados referentes à pesquisa realizada nas micro e pequenas empresas de Porto Velho.

Para a realização da presente pesquisa utilizou-se como amostra 30 micro e pequenas empresas, distribuídas da seguinte forma: 10 no centro, 10 na zona sul e 10 na zona leste.

Em seguida, foi realizada a distribuição de questionários para que os micro e pequenos empresários respondessem. No geral, as perguntas foram prontamente respondidas.

Com vistas a facilitar a compreensão das informações obtidas, os dados foram divididos em três grupos: apresentação do perfil das empresas, influência e utilização da contabilidade de custos na formação do preço de venda e assessoria de um contador para formar os preços. 
No decorrer da pesquisa, em respeito ao pedido da maioria das empresas, optou-se por não revelar os nomes das mesmas. Por fim, foi feita a análise dos dados onde os mesmos foram avaliados e discutidos para enfim concluirmos.

\subsection{APRESENTAÇÃO DO PERFIL DAS EMPRESAS}

Tendo em vista o fato da presente pesquisa ter sido realizada com empresas diversificadas, com localização diferente, tempo de atividade diferente, entre outros aspectos, se fez necessário traçar um perfil das referidas empresas. Para traçar este perfil foram feitas algumas perguntas que permitam tal feito, como: tempo de atividade, setor de atuação, localização e natureza jurídica.

\subsubsection{TEMPO DE ATIVIDADE}

No decorrer da pesquisa, buscou-se conhecer a quanto tempo as empresas estão no mercado. Para tanto as mesmas foram agrupadas em grupos, a saber: entre 2 e 10 anos, entre 11 e 20 e entre 21 a 40 anos, conforme demonstrado no gráfico 1:

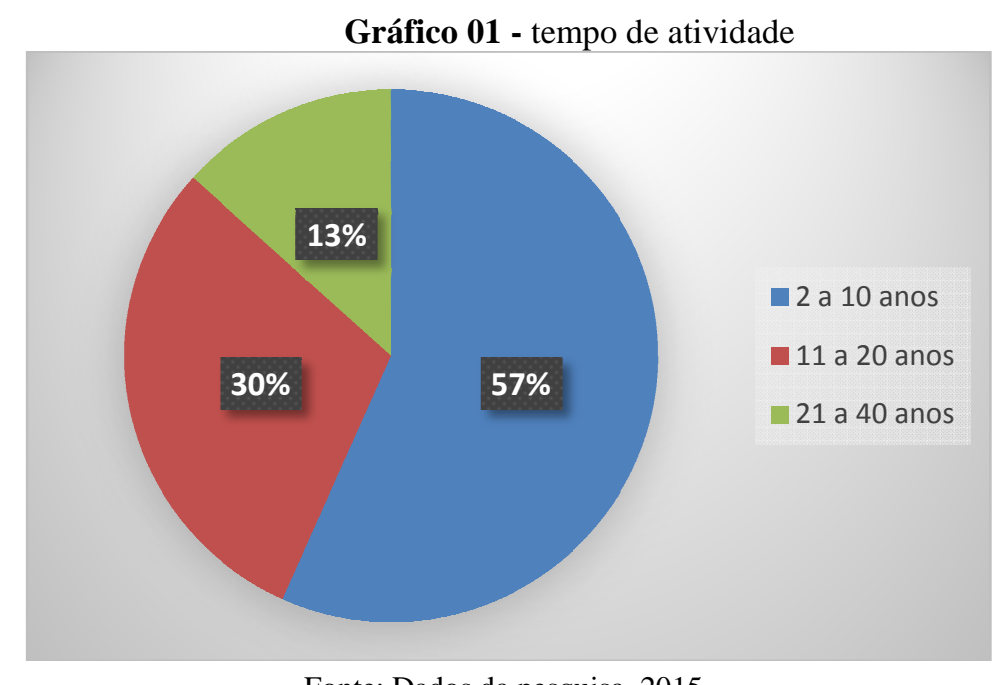

Fonte: Dados da pesquisa, 2015.

Pode-se observar nos dados obtidos que das empresas pesquisadas 17 ou $57 \%$ estão no mercado entre 2 e 10 anos, seguidas por 9 ou $30 \%$ que estão no mercado entre 11 e 20 anos e 4 ou $13 \%$ que estão em atividade entre 21 e 40 anos.

\subsubsection{SETOR DE ATUAÇÃO}

Buscando uma homogeneidade, optou-se nesta pesquisa por utilizar apenas empresas que atuam no comércio, logo as 30 empresas pesquisadas fazem parte deste setor. Desta 
forma foi possível analisar os dados delas de forma igual, e notar com mais nitidez a influência que o uso da contabilidade de custos e a assistência de um contador, têm na hora de formar o preço.

\subsubsection{LOCALIZAÇÃO}

Com o objetivo de contemplar da maior maneira possível a cidade de Porto velho, a pesquisa foi realizada nas três regiões com maior concentração de comerciantes, quais sejam estas: zona norte, zona sul e zona leste. As quantidades de empresas que responderam aos questionários foram iguais para as três regiões.

\subsubsection{NATUREZA JURÍDICA}

A pesquisa se delimitou a descobrir a influência da contabilidade de custos e do contador no processo de formação do preço de venda das micro e pequenas empresas. Dentro desta delimitação constatamos o que segue no gráfico 2 :

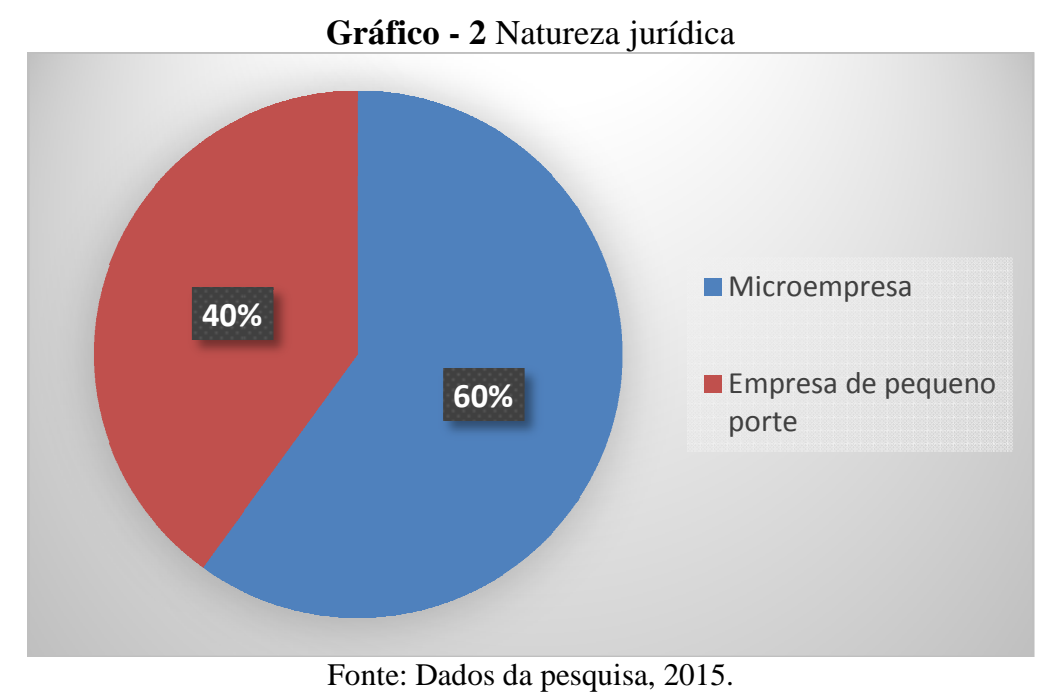

Das empresas pesquisadas 18 ou $60 \%$ são microempresas, o restante $40 \%$ ou 12 são empresas de pequeno porte.

\subsubsection{INFLUÊNCIA E UTILIZAÇÃO DA CONTABILIDADE DE CUSTOS NA FORMAÇÃO DO PREÇO DE VENDA}

Com o objetivo de descobrir se os micro e pequenos empresários utilizam a contabilidade de custos e s diversas ferramentas por ela oferecida, e de que forma isso influência em sua maneira de pensar preços, algumas questões foram propostas: a empresa conhece todos os seus custos? Ao formar o preço de venda são considerados os preços 
praticados pelo mercado? A empresa utiliza o preço de venda como estratégia de marketing, para atrair consumidores? e qual o nível de importância que sua empresa dá para a contabilidade de custos na formação do preço de venda?

\subsubsection{A EMPRESA CONHECE TODOS OS SEUS CUSTOS?}

Segundo Hong (2006) os consumidores estão cada vez mais exigentes, em busca de produtos com alta qualidade e bom atendimento tudo há preços baixos. Para conseguir continuar no mercado oferecendo os preços baixos exigidos a empresa deve possuir uma estrutura de custos eficaz, o que será determinante para a sobrevivência das entidades nos próximos anos. Diante disso, os micro e pequenos empresários de Porto Velho devem aprimorar seus conhecimentos sobre seus custos.

Gráfico 03 - A empresa conhece todos os seus custos?

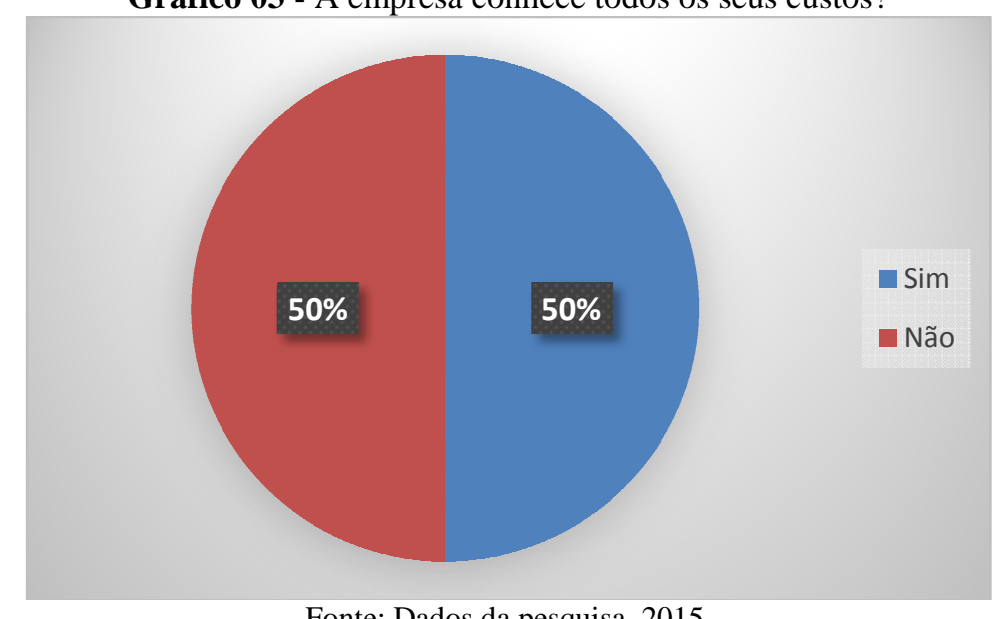

Fonte: Dados da pesquisa, 2015.

Pode-se observar, no gráfico 3 , que $50 \%$ das empresas afirmam conhecer todos os seus custos, porém quando indagas acerca de algumas questões simples como, por exemplo: quais são seus custos variáveis? Quando se deve classificar um gasto como investimento? Não souberam ou tiveram dificuldade em responder.

\subsubsection{AO FORMAR O PREÇO DE VENDA SÃO CONSIDERADOS OS PREÇOS PRATICADOS PELO MERCADO?}

No desenrolar da pesquisa observou-se que no fim quem acaba ditando as regras é o mercado, afinal, de nada adiantaria obter um preço excelente para a empresa no que diz respeito a seus custos e maximização de lucros, se ele não pode ser praticado, ou seja, se ele não for compatível com o mercado. 
Gráfico 04 - Ao formar o preço de venda são considerados os preços praticados pelo mercado?

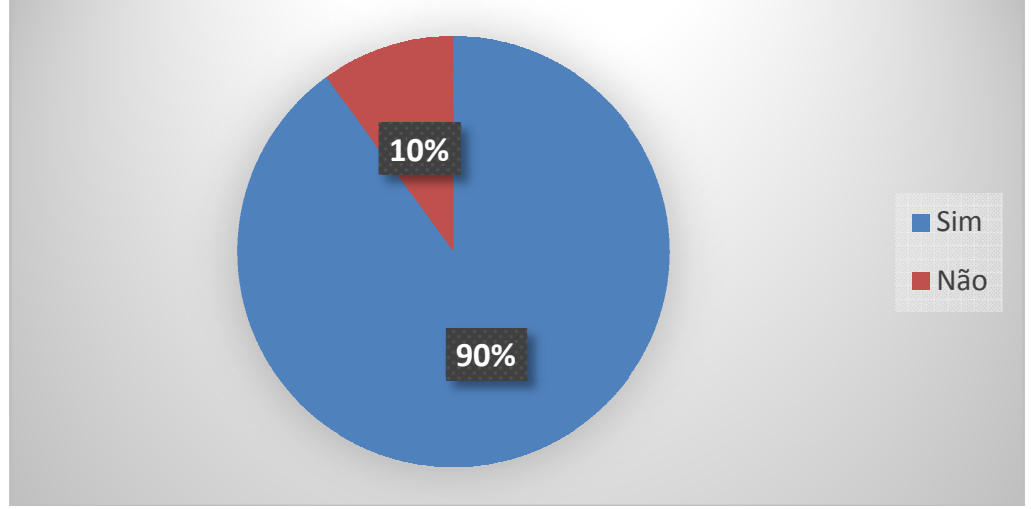

Fonte: Dados da pesquisa, 2015.

Pode-se perceber, conforme demonstrado no gráfico 4, que 27 empresas, que representam $90 \%$ da amostra, consideram os preços praticados pelo mercado ao formarem seus preços, ao passo que 3 empresas ou $10 \%$ não consideram o que é praticado no mercado.

\subsubsection{A EMPRESA UTILIZA O PREÇO DE VENDA COMO ESTRATÉGIA DE MARKETING, PARA ATRAIR CONSUMIDORES?}

Ao lado da qualidade, o preço é, sem dúvida, a maior preocupação na hora da compra, sabendo disto a maioria das empresas utiliza o próprio preço como uma estratégia de marketing um exemplo claro disto são as promoções.

Gráfico 05 -A empresa utiliza o preço de venda como estratégia de marketing, para atrair consumidores?

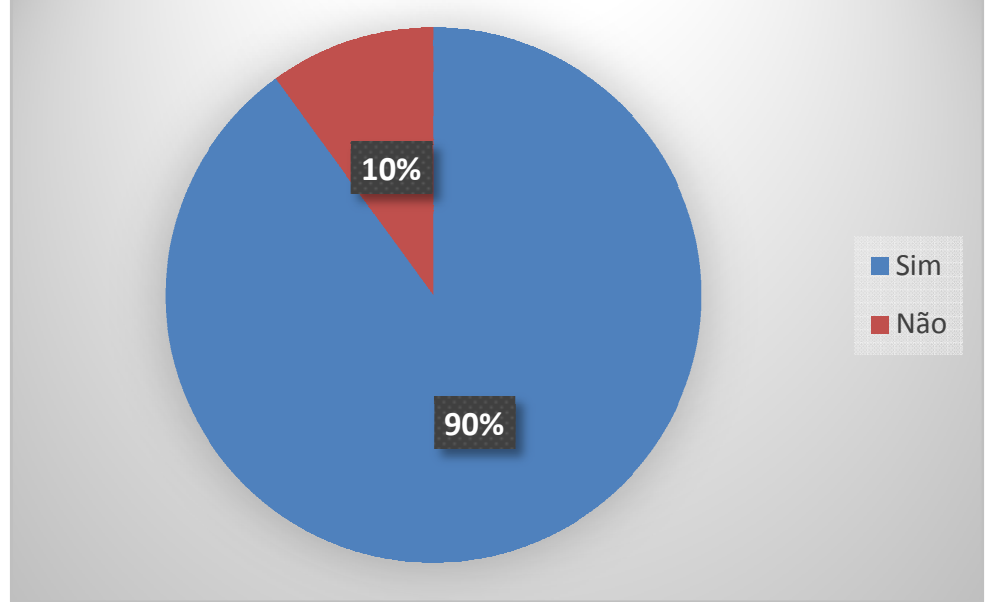

Fonte: Dados da pesquisa, 2015. 
Ficou demonstrado no gráfico 5 que $90 \%$ dos administradores entendem que o preço de venda é uma importante ferramenta para atrair consumidores, $10 \%$ não utiliza esta técnica.

Gráfico 06 - Nível de importância que sua empresa dá para a contabilidade de custo na formação do preço de venda.

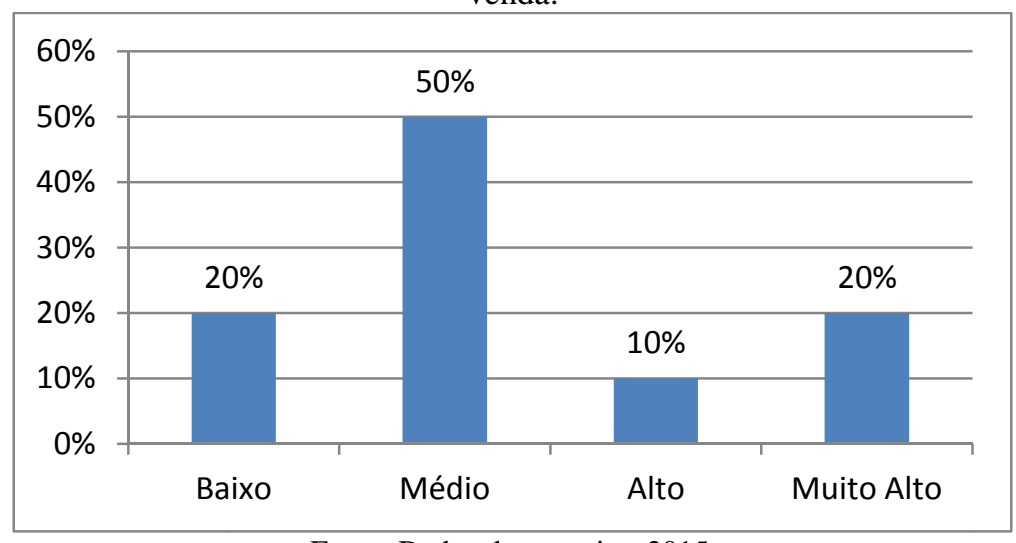

Fonte: Dados da pesquisa, 2015.

Observando o gráfico 6, 20\% das empresas consideram baixa a importância da contabilidade de custos, 15 ou 50\% das empresas consideram média, 3 empresas ou 10\% consideram alta e 6 empresas ou 20\% consideram muito alta a importância da contabilidade de custos na formação do preço de venda.

\subsubsection{ANÁLISE DOS DADOS}

Para ter um melhor entendimento sobre a pesquisa é interessante analisarmos questionamentos e gráficos de forma conjunta. No gráfico 03, 50\% dos empresários afirmaram conhecer todos os seus custos, porém destes, apenas $25 \%$ não tiveram dificuldades de responder sobre alguns de seus custos e despesas. Em outros questionamentos foi possível observar que os gestores dessas empresas consideram de grande importância o mercado e marketing na hora de formar preço, e, $70 \%$ deles acham que a contabilidade de custo tem um grau de importância de médio para baixo, quando se trata de formação de preço. Diante desse cenário, onde grande parte dos gestores não conhece seus custos e não acha relevante conhecer, os mesmos fixam seus preços somente com base no mercado e elaboram estratégias de marketing, correndo o risco de criar seus preços de forma que não retrate sua realidade, podendo incorrer em prejuízos e até inviabilizar seu negócio. 


\subsubsection{ASSESSORIA DE UM CONTADOR NA FORMAÇÃO DO PREÇO DE VENDA}

$\mathrm{Na}$ presente pesquisa procurou-se descobrir se os micro e pequenos empresários utilizam a assistência de um contador para formarem seus preços, tendo em vista o conhecimento técnico que este profissional possui no que diz respeito à contabilidade de custos, e, por conseqüência, na formação de preços.

Segundo Marion (2012, p.27):

A função básica do contador é produzir informações úteis aos usuários da contabilidade para a tomada de decisões. Ressaltemos, entretanto, que, em nosso país, em alguns segmentos de nossa economia, principalmente na pequena empresa, a função do contador foi distorcida (infelizmente), estando voltada exclusivamente satisfazer as exigências do fisco.

Gráfico 7 - A empresa possui a assistência de um contador para a formação de seu preço de venda?

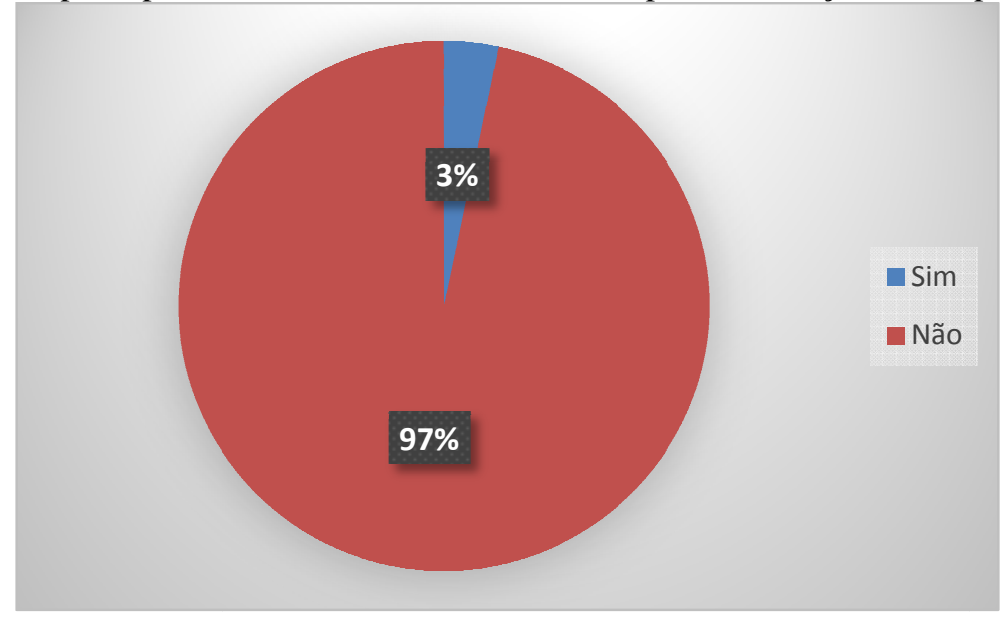

Fonte: Dados da pesquisa, 2015.

Observando o gráfico 7, percebe-se que apenas $3 \%$ ou 1 empresa do total de trinta pesquisadas utilizam a assistência do contador para formarem seus preços, logo 29 empresas ou 97\% não utilizam a referida assistência, foi possível notar que a esmagadora maioria utiliza a assistência do contador somente para a parte fiscal, desconhecendo o potencial que este profissional possui para produzir informações de suma importância para o gerenciamento da empresa e tomada de decisões, englobando nisto a formação de seus preços.

A contabilidade de custos fornece inúmeras ferramentas para gestão, porém uma pessoa leiga em contabilidade dificilmente conseguirá extrair seus benefícios em sua totalidade, neste momento surge a figura do contador, o profissional que vai fazer a ligação entre a informação oferecida pela contabilidade de custos e o empresário.

É possível notar com frequência que as micro e pequenas empresas enfrentam problemas para serem empresas competitivas e se manterem no mercado, e os principais 
motivos citados por esses empresários são as altas cargas tributárias, os encargos sociais, juros altos, entre outros. Porém, quando investigado mais a fundo, os fatores preponderantes não são estes, mas sim o mau gerenciamento, onde decisões são tomadas utilizando uma contabilidade irreal que foi feita exclusivamente para atender ao fisco. (MARION,2012)

\section{CONSIDERAÇÕES FINAIS}

Esta pesquisa se propôs a identificar a contribuição da contabilidade de custos e do profissional contador, como vantagem competitiva na formação do preço de venda das micro e pequenas empresas do município de Porto velho. Foi utilizado um vasto referencial teórico onde ficou constatado que a contabilidade de custo é uma ferramenta que traz inúmeros benefícios ao gestor na hora de formar seu preço, e que o contador é o profissional especializado para produzir essas informações e interpretar, de modo a prestar uma assessoria fundamental nas tomadas de decisões das empresas.

Foram realizadas pesquisas de campo nas micro e pequenas empresas do município de Porto Velho, onde ficou evidenciado que os gestores dessas empresas muitas vezes não têm conhecimento dessa vantagem competitiva que a contabilidade de custo e a assessoria de um contador podem trazer para suas empresas, e, até mesmo que a maioria deles tem uma ideia distorcida sobre o assunto. O que se observa é um mau gerenciamento de forma geral o que, em um futuro próximo, pode levar à extinção de algumas dessas entidades. Em Porto Velho a maioria das empresas faz parte do grupo das micro e pequenas empresas, o que ficou evidenciado pela pesquisa de campo e verificação à junta comercial de Rondônia, o que torna extremamente relevante que se amplie os estudos, que informem e orientam os gestores sobre como uma boa estrutura de custos e uma assessoria especializada podem ser usadas como um diferencial em um mercado que tem preços cada vez mais agressivos como o de Porto Velho.

\section{REFERÊNCIAS}

CREPALDI, Silvio Aparecido. Curso básico de contabilidade de custos. $5^{\mathrm{a}}$ ed. São Paulo: Atlas, 2010.

DINIZ, Josélia Aves Rafael. O Planejamento de Vendas como Instrumento de Gestão e Diferencial Competitivo de Mercado: Um estudo nas Micro e Pequenas Empresas do Município de Catolé do Rocha - PB. 2008. 82 f. Monografia (Graduação em Ciências Contábeis) - Universidade Federal de Campina Grande, Sousa, PB, 2008.

DUBOIS, Alexy; KULPA, Luciana; SOUZA Luiz Eurico. Gestão de Custos e Formação de Preços. São Paulo: Atlas, 2006. 
DUTRA, René Gomes. Custos: Uma abordagem prática. 5ª ed. São Paulo: Atlas, 2003.

FIGUEIREDO, Sandra, CAGGIANO, Paulo Cesar. Controladoria: Teoria e Prática. $4^{a}$ ed.São Paulo: Atlas, 2008.

GIL, Antônio Carlos. Como elaborar projetos de pesquisa. 4ª ed. São Paulo: Atlas, 1999.

HOJI, Masakasu. Administração Financeira: uma abordagem prática: matemática financeira aplicada, estratégias financeiras, análise, planejamento e controle financeiro. $5^{\mathrm{a}}$ ed. São Paulo: Atlas, 2004.

HONG, Yuh Ching. Contabilidade Gerencial: novas práticas contábeis para a gestão de negócios. $1^{a}$ ed. São Paulo: Pearson Prentice Hall, 2006.

HORNGREN, Charles T.; FOSTER, George; DATAR, Srikant M. Contabilidade de custos. $2^{\mathrm{a}}$ ed. Rio de Janeiro: LTC, 2000.

MARION, José Carlos. Contabilidade Empresarial. 16ª ed. São Paulo: Atlas, 2012.

MARTINS, Eliseu. Contabilidade de Custos. 7ª edição, São Paulo: Atlas, 2000.

PADOVEZE, Clóvis Luís. Contabilidade Gerencial: um enfoque em sistema de informação contábil.1 ${ }^{a}$ ed. São Paulo: Atlas, 1994.

QUEIROZ, Amanda Batista de. Um Estudo sobre o Custeio por Absorção: O caso da Microempresa Fabricante de Argamassa e Reboco Pronto, Net Cola Indústria e Comércio, situada no Município de Juazeirinho - Paraíba. 2012. 22 f. trabalho de conclusão de curso curso de Ciências Contábeis, Universidade Estadual da Paraíba, Campina Grande, 2012.

SIENA, Osmar. Metodologia da Pesquisa Científica: elementos para elaboração e apresentação de trabalhos. Porto Velho: [s.n.], 2007200 p.

SANTOS, Edno Oliveira dos. Administração Financeira da Pequena e Média Empresa. $2^{\text {a }}$ edição, São Paulo: Atlas, 2010.

SOUZA, Antônio Carlos Breves de; PINTO Junior; Dario Moreira; OLIVEIRA, José Vilmar de. Uma Análise sobre o Preço de Venda nas Empresas Prestadoras de Serviços na Cidade de Barra Mansa - Rio de Janeiro. Revista Brasileira de Gestão e Engenharia - ISSN 2237-1664 Centro de Ensino Superior de São Gotardo, São Gotardo, n. III Jan-jun. p. 47-67, 2011. 